\title{
QUANTIFICAÇÃO DE MACRONUTRIENTES EM FLORESTA OMBRÓFILA MISTA MONTANA UTILIZANDO DADOS DE CAMPO E DADOS OBTIDOS A PARTIR DE IMAGENS DO SATÉLITE IKONOS II
}

\author{
Vanessa Canavesi*, Flávio Felipe Kirchner** \\ *Eng ${ }^{\text {a }}$. Florestal, M.Sc., Doutoranda em Sensoriamento Remoto, INPE - vacanavesi@bol.com.br \\ **Eng. Florestal, Dr., Depto. de Ciências Florestais da UFPR - kirchner@floresta.ufpr.br \\ Recebido para publicação: 12/02/2004 - Aceito para publicação: 12/12/2005
}

\begin{abstract}
Resumo
Quantificação de macronutrientes em Floresta Ombrófila Mista Montana utilizando dados de campo e dados obtidos a partir de imagens do satélite IKONOS II. O objetivo deste trabalho foi desenvolver uma metodologia para estimar os macronutrientes $(\mathrm{N}, \mathrm{P}, \mathrm{K}, \mathrm{S}, \mathrm{Ca}$ e $\mathrm{Mg}$ ) presentes em uma floresta nativa, utilizando dados espectrais provenientes de satélite de alta resolução, IKONOS II, e dados de campo. As amostras de biomassa foram coletadas em 20 parcelas distribuídas em vários estágios sucessionais da floresta. Os teores de nutrientes em cada espécie foram obtidos em análises de laboratório, e a quantificação por parcela foi feita multiplicando-se esses teores pela biomassa seca. Por meio de análise estatística, relacionaram-se as quantidades de nutrientes nas parcelas com os dados obtidos nas imagens de satélite. Os valores de reflectância nas bandas MS-1, MS-2, MS-3, MS4 e os índices de vegetação NDVI, SAVI e Razão de Bandas entraram no modelo como variáveis independentes, e os nutrientes, como dependentes. Foram geradas equações alométricas, o que permitiu a quantificação e o mapeamento dos nutrientes para a área.

Palavras-chave: Macronutrientes; sensoriamento remoto; modelos de predição; Araucaria angustifolia.
\end{abstract}

\begin{abstract}
Estimate macronuntrients content in mixed ombrophylus forest using field data and data from satelite image IKONOS II. The main objective of this research work was to develop a methodology to estimate nutrient ( $\mathrm{N}, \mathrm{P}, \mathrm{K}, \mathrm{S} \mathrm{Ca}$ and $\mathrm{Mg}$ ) content in a pristine Araucarian forest using spectral data from high resolution IKONOS II satellite and field data. Samples for biomass estimates were collected in 20 plots distributed over several growth stages of secondary forest. Nutrient contents in each species were obtained from analysis in a laboratory and total amount in the plots was calculated by multiplying nutrient concentration by dry biomass. Statistical analysis provided the nutrient content and satellite data relation. The reflectance of MS-1, MS-2, MS-3, MS-4 bands and NDVI, SAVI and band ratio were input in the model as independent variables, while nutrients content were the dependent variables. Allometric equations were developed for estimates to the entire area. Keywords: Macro-nutrients; remote sensing; prediction models; Araucaria angustifolia.
\end{abstract}

\section{INTRODUÇÃO}

Estudos envolvendo quantificação de biomassa de maneira indireta, ou seja, não destrutiva, tiveram início na década de 80. Em florestas plantadas, o entendimento do ciclo do carbono, nitrogênio e outros nutrientes tem feito com que a exploração florestal inove seus princípios.

Sabe-se que grande parte dos nutrientes presentes em uma árvore se concentra nas folhas, galhos e casca. A quantificação dos nutrientes nesses componentes tem contribuído para que as operações florestais sejam feitas de uma maneira mais racional, em que restos de culturas, que antes eram descartados, sejam incorporados ao solo, diminuindo assim a degradação deste e a demanda por 
fertilizantes. Nas florestas nativas, é importante saber quanto dos nutrientes é fixado pelas plantas e qual o ganho que o meio ambiente terá com a preservação desses ecossistemas.

Cerri et al. (2001) relatam que os macronutrientes estão presentes principalmente nas partes sólidas do solo. Entre os primários, tem-se o nitrogênio $\left(\mathrm{NO}_{3}^{-}, \mathrm{NH}_{4}^{+}\right)$, o fósforo $\left(\mathrm{H}_{2} \mathrm{PO}_{4}^{-}, \mathrm{HPO}_{4}{ }^{2-}\right)$ e o potássio $\left(\mathrm{K}^{+}\right)$. Já os secundários são o cálcio $\left(\mathrm{Ca}^{2+}\right)$, o magnésio $\left(\mathrm{Mg}^{2+}\right)$ e o enxofre $\left(\mathrm{SO}_{4}{ }^{2-}\right)$. A planta retira nutrientes do ar, da água e do solo. $\mathrm{O}$ carbono vem do ar, o hidrogênio vem da água e o oxigênio vem da água e do ar. Os demais elementos vêm do solo, o que o torna de importância vital para as plantas, especialmente por ser o meio em que o homem mais consegue interferir, com adubações e correções de $\mathrm{pH}$ (Malavolta, 1979).

Para o mesmo autor, os macronutrientes representam mais de $0,1 \%$ da matéria seca das plantas. Estão presentes em maior ou menor proporção no solo, dependendo da composição e estrutura da rocha em que o solo foi originado, dos resíduos orgânicos presentes nesse solo, bem como do clima e topografia do terreno. Esses nutrientes são quantificados a partir de amostras destrutivas no campo. Os dados provenientes dessas amostras são utilizados para determinar equações alométricas que estimam a biomassa para a área como um todo. Parâmetros como diâmetro à altura do peito, altura da árvore, altura da base da copa, entre outros, podem ser utilizados como variáveis do modelo (Miller, 1984; Santos, 1989; Nilsson \& Wiklund, 1995).

Modelagens de alguns ciclos, como o do carbono e do nitrogênio, já são realizadas a partir de medições no campo comparadas com dados de imagens de satélite (Lacruz et al., 2001). Técnicas de sensoriamento remoto têm sido utilizadas na área florestal, incluindo trabalhos de quantificação de biomassa e carbono, possibilitando estimar a quantidade de carbono que as florestas estão fixando. Essas técnicas ainda são pouco empregadas, seja pela heterogeneidade das florestas, seja pela dificuldade de aquisição de imagens em certas áreas.

Este estudo teve como objetivo desenvolver uma metodologia para estimar as quantidades de macronutrientes em uma Floresta Ombrófila Mista, utilizando imagens de satélite IKONOS II e dados de campo.

\section{REVISÃO BIBLIOGRÁFICA}

\section{Os nutrientes e as plantas}

Segundo Larcher (1986), a absorção de nutrientes do solo pelas raízes das plantas se dá de três maneiras: pela absorção de íons nutrientes da solução do solo (íons diretamente disponíveis, com baixas concentrações no solo: $\mathrm{NO}_{3}^{-}, \mathrm{SO}_{4}{ }^{+}, \mathrm{Ca}^{2+}, \mathrm{Mg}^{2+}, \mathrm{K}^{+}$e Fosfato); pela absorção por troca de íons de nutrientes adsorvidos (trocando íons de $\mathrm{H}^{+}$e $\mathrm{HCO}_{3}$, as raízes obtêm íons de nutrientes) e por liberação de estoques de nutrientes ligados por meio de íons $\mathrm{H}^{+}$excretados e ácidos orgânicos. Este último depende da intensidade da respiração, da temperatura, do tipo de íon e da espécie vegetal. Os elementos nutritivos são incorporados em maior ou em menor quantidade, dependendo do estágio de crescimento da planta. É durante o crescimento da planta que grande parte desses nutrientes é incorporada, e uma menor quantidade é requerida quando a planta atinge a maturidade. Nessa fase, a taxa de absorção de minerais é menor do que a de absorção de matéria orgânica.

O transporte de nutrientes dentro da planta se inicia quando os minerais atingem o xilema na raiz e caminham de forma ascendente (no sentido da corrente respiratória), para que ocorra sua distribuição. Os minerais passam do xilema para o floema através do câmbio, permitindo assim que parte dos minerais fique retida ou desviando-os para que não sejam totalmente levados para a corrente respiratória. A partir do momento em que o nutriente entra para o floema, ele está livre para circular em todas as direções: para baixo, para cima e para os lados. A chegada dos minerais até as folhas não faz com que a circulação termine, ou seja, eles estão sempre se movimentando dentro da planta. A mobilidade dos elementos dentro do floema é a seguinte: $\mathrm{N}>\mathrm{K}>\mathrm{Na}>\mathrm{P}>\mathrm{Cl}>\mathrm{S}>\mathrm{Zn}>\mathrm{Cu}>\mathrm{Mn}>\mathrm{Fe}>\mathrm{Mo}>\mathrm{Mg}$; o Ca e o B são imóveis. A circulação desses elementos dentro da planta é muito variável, desde sua absorção pelas raízes até a sua redistribuição, quando o elemento atinge as folhas (Malavolta, 1979).

Há uma forte relação desses nutrientes com a reflectância das plantas. A deficiência mineral pode trazer alterações nas concentrações de clorofila e pode afetar também a estrutura interna das folhas. Essas modificações foliares são percebidas na resposta da vegetação no espectro eletromagnético. 


\section{Comportamento espectral da vegetação}

As diferentes formas de vegetação agem diferentemente na absorção e reflectância das ondas do espectro eletromagnético. Para se entender porque a vegetação reflete mais certos comprimentos de onda, é necessário primeiro considerar as propriedades de reflectância de uma folha individual. Curran (1986) relata que a folha é constituída de uma estrutura fibrosa de matéria orgânica, dentro da qual há pigmentos, células contendo água e espaços de ar. Cada um desses três elementos (pigmentação, estrutura fisiológica e conteúdo de água) produz efeito nas propriedades de reflectância, absortância e transmitância da folha verde (Figura 1).

A cobertura vegetal sadia tem uma alta interação com energia na região de comprimento de ondas visível e infravermelho próximo. A região do visível $(0,4$ a $0,7 \mu \mathrm{m})$ é a parte do espectro eletromagnético utilizada pelas plantas para a fotossíntese, o que explica a forte absorção de energia nesses comprimentos de onda e, por conseqüência, baixa reflectância e baixa transmitância. Essa alta absorção está concentrada na região do azul e do vermelho. A luz verde é absorvida pelas plantas em menor quantidade do que as luzes azul e vermelha, fazendo com que ela seja refletida mais do que estas últimas, o que dá a aparência verde às folhas (Thiam e Eastman, 1999; Verbyla, 1995).

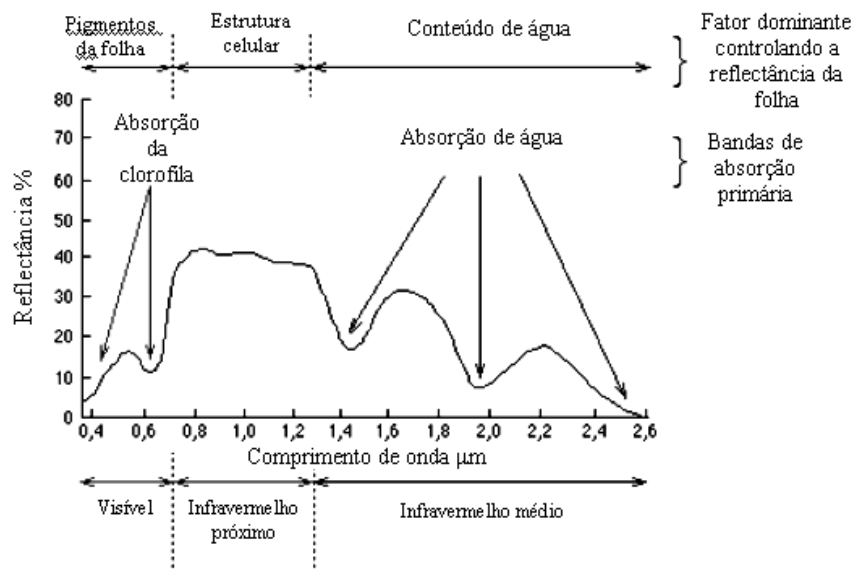

Figura 1. Comportamento espectral da vegetação no espectro eletromagnético.

Figure 1. Vegetation spectral behavior in the electromagnetic spectrum.

Fonte: Propriedades ópticas da vegetação e do solo (2004).

No infravermelho, há um aumento significativo da reflectância quando se compara com a região visível do espectro eletromagnético. Nessa região, a vegetação verde é caracterizada pela alta reflectância, alta transmitância e baixa absortância. Essas quantidades podem variar com o tipo de vegetação, mas geralmente as plantas apresentam de 45 a $50 \%$ de reflectância, 40 a $50 \%$ de transmitância e $5 \%$ de absortância nos comprimento de onda do infravermelho próximo (Hoffer, 1978).

A energia nessa região não é utilizada pela fotossíntese, sendo a estrutura interna das folhas a responsável pela alta reflectância (Thiam e Eastman, 1999). A estrutura interna das folhas da planta é muito complexa e controla a resposta espectral nessa porção do espectro. Essas diferenças podem ser utilizadas para separar culturas (Hoffer, 1978).

O conteúdo de água presente nas folhas também afeta a reflectância, sendo mais acentuada na região do infravermelho. A reflectância é reduzida, como resultado de bandas de absorção de água presentes no espectro de uma folha. Há três bandas maiores de absorção de água, que ocorrem nos comprimentos de onda de $1,4 \mu \mathrm{m}, 1,9 \mu \mathrm{m}$ e $2,7 \mu \mathrm{m}$, e duas bandas menores, que ocorrem a $0,96 \mu \mathrm{m}$ e 1,1 $\mu \mathrm{m}$. A reflectância no interior das folhas nesses comprimentos de onda é negativamente relacionada tanto para a quantidade de água na folha quanto para a espessura. Entretanto, a água da atmosfera também absorve radiação nesses comprimentos de onda, e por essa razão a maioria dos sensores operam nas três janelas atmosféricas que estão livres da absorção de água nos comprimentos de onda de 0,3 a 1,3 $\mu \mathrm{m} ; 1,5$ 
a $1,8 \mu \mathrm{m}$ e 2,0 a 2,6 $\mu \mathrm{m}$. Nesses comprimentos de onda, a radiação eletromagnética é sensível à umidade da folha (Hoffer, 1978).

\section{Sensoriamento Remoto na estimativa de biomassa}

O sensoriamento remoto pode ser utilizado para estimar a biomassa vegetal. Para isso são necessárias parcelas de campo cujos dados são correlacionados com as imagens obtidas por sensores remotos. Alguns trabalhos nessa linha foram desenvolvidos por vários autores e apresentados a seguir.

Zerbini (1992) desenvolveu, na floresta amazônica, uma metodologia para quantificação de fitomassa aérea de floresta tropical a partir de dados espectrais obtidos de imagens TM Landsat 5 e HRVSPOT 1. Foram determinadas as correlações entre variáveis dendrométricas, espectrais, de cota e fitomassa aérea, e, por meio de análise de regressão, foram geradas as equações de quantificação de biomassa.

Um estudo feito em três regiões diferentes (Amazônia-Brasil, Tailândia e Malásia) para estimar biomassa utilizando imagens de satélite e redes neurais foi realizado por Foddy et al. (2003). A biomassa $\left(\right.$ Ton.ha $^{-1}$ ) em cada amostra foi tomada somando-se a biomassa total acima do solo para os componentes das árvores estimados $(\mathrm{kg})$ utilizando-se equações alométricas. Os pixels contendo a unidade amostral foram identificados e as reflectâncias nas bandas 1, 2, 3, 4, 5 e 7 do satélite Landsat TM foram extraídas para análise.

Dong et al. (2003) fizeram estimativas de carbono em floresta boreal e temperada utilizando o sensoriamento remoto. A biomassa de carbono foi estimada estatisticamente por modelos de regressão, onde foram estudadas as relações entre a imagem de satélite contendo o índice NDVI (Normalized Difference Vegetation Index) e o conteúdo de carbono na biomassa florestal estimado por meio de inventário. Foram então avaliados a capacidade de modelos de regressão de representar a relação entre a biomassa e o NDVI utilizando escalas espacial, temporal e ecológica.

Gaveau et al. (2003) realizaram um trabalho na Sibéria Central em que classificaram a biomassa de uma floresta com base em imagens de radar. Inventários florestais foram realizados, e para cada parcela obtiveram-se dados sobre: categoria de cobertura do solo, estoque relativo de madeira, volume de estoque crescente, idade, composição de espécies, altura média e diâmetro à altura do peito. Esses dados foram extrapolados para a área total. Foram então atribuídas classes de volume para a área e, por meio de um Sistema de Informações Geográficas, foi gerado um mapa de volume por hectare.

Watzlawick (2003) realizou um estudo em reflorestamento de Pinus, Araucária e floresta nativa, desenvolvendo metodologia para estimar biomassa e carbono por meio de amostras de campo (destrutivas) e dados do satélite IKONOS II. Nas parcelas, foram amostrados dados da vegetação arbórea, arbustiva, serapilheira e raízes. Esses dados foram relacionados com as imagens de satélite e foram geradas equações que permitiram estimar biomassa e carbono nas parcelas e extrapolar os dados para a área toda. $\mathrm{O}$ produto final foi o mapeamento do carbono para as diversas tipologias florestais estudadas.

\section{MATERIAIS E MÉTODO}

\section{Área de estudo}

A área está localizada na Região Centro Sul do Paraná, entre as coordenadas $26^{\circ} 20^{\prime} 35^{\prime \prime}$ e $26^{\circ}$ 26' 13" Latitude Sul e $51^{\circ} 19^{\prime} 49^{\prime \prime}$ e $51^{\circ} 25^{\prime} 29^{\prime \prime}$ Longitude Oeste, com uma altitude média de $1000 \mathrm{~m}$ s.n.m. (Paraná, 1987) e a $280 \mathrm{~km}$ de Curitiba, no município de General Carneiro (Figura 2). Nessa área está sendo desenvolvido um Projeto Ecológico de Longa Duração (PELD Site 9), o "Bioma Floresta de Araucária e suas Transições", com a implementação de vários trabalhos.

Segundo Yamaji (2001), da área total, 2719 ha são áreas de floresta e áreas de Reserva Legal, representando $64,57 \%$ do total das propriedades. O restante está dividido da seguinte forma: 72 ha são áreas de Preservação Permanente ( $1,71 \%$ do total) e reflorestamentos com 1287 ha (30,56\% do total), e 133 ha estão ocupados por estradas, construções e cursos d'água. A área total da fazenda é de 4211 ha.

A área estudada possuía 70 unidades amostrais locadas, utilizando o método de amostragem de área fixa e o processo sistemático, em que cada parcela (ou unidade amostral) ocupava uma área de 2500 $\mathrm{m}^{2}(25 \times 100 \mathrm{~m})$. Watzlawick (2003) sorteou aleatoriamente 20 parcelas, das 70 existentes, para quantificar a biomassa. Dentro de cada unidade amostral sorteada, foram locadas subunidades de $12 \times 12$ $\mathrm{m}$ (unidade amostral primária), localizadas no canto inferior esquerdo da parcela maior, as quais foram 
utilizadas para este trabalho. Essas dimensões foram escolhidas porque o pixel da imagem IKONOS II é de $4 \mathrm{~m}$, o que na imagem resulta uma parcela de $3 \times 3$ pixels.

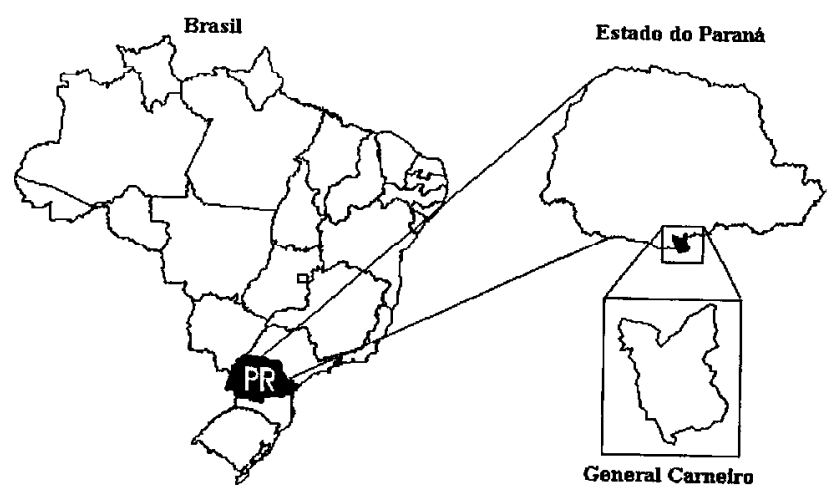

Figura 2. Mapa de localização da área de estudo.

Figure 2. Study area localization.

Fonte: Caldeira (2003)

A distribuição das parcelas dentro dos estágios sucessionais amostrados é apresentada na tabela 1. A propriedade já sofreu várias interferências antrópicas, e as tipologias florestais presentes nos domínios da fazenda demonstram estar em pleno desenvolvimento, o que pode ser percebido pela área ocupada pela floresta secundária no estágio intermediário de sucessão.

Tabela 1. Distribuição das parcelas de acordo com os estágios sucessionais da Floresta Ombrófila Mista. Table 1. Sample distribution by growth stages of Mixed Ombrophylus Forest.

\begin{tabular}{cc}
\hline & Estágio Sucessional \\
\hline 1 & Floresta Secundária Inicial \\
2 & Floresta Secundária Intermediária \\
3 & Floresta Secundária Avançada \\
4 & Floresta Secundária Intermediária \\
5 & Floresta Secundária Avançada \\
6 & Floresta Secundária Intermediária \\
7 & Floresta Secundária Intermediária \\
8 & Floresta Secundária Intermediária \\
9 & Floresta Secundária Avançada \\
10 & Floresta Secundária Intermediária \\
11 & Floresta Secundária Avançada \\
12 & Floresta Secundária Inicial \\
13 & Floresta Secundária Intermediária \\
14 & Floresta Secundária Intermediária \\
15 & Floresta Secundária Intermediária \\
16 & Floresta Secundária Intermediária \\
17 & Floresta Secundária Avançada \\
18 & Floresta Secundária Intermediária \\
19 & Floresta Secundária Intermediária \\
20 & Floresta Secundária Avançada \\
\hline
\end{tabular}

Determinação da biomassa no campo e cálculo dos teores dos nutrientes

Para 20 parcelas ( $12 \times 12 \mathrm{~m})$, locadas na área de estudo, foram abatidos todos os indivíduos com DAP maior ou igual a $10 \mathrm{~cm}$. Foram separados os componentes: folhas, galhos, fuste, casca e miscelânea, a qual continha frutos, flores, lianas, bromélias, musgos, líquens e orquídeas. Todo o material foi pesado e quantificado, e foram determinadas a biomassa verde e a seca (Watzlawick, 2003). 
Foram selecionados três exemplares de cada espécie para aquelas com DAP acima de $10 \mathrm{~cm}$ (DAP maior, médio e menor), e para aquelas que não tinham mais de três exemplares, todas foram utilizadas para a determinação do teor dos nutrientes. Para a casca e o fuste, fez-se uma média das duas amostras. Amostras de material separadas por espécie e por componente da árvore foram submetidas a testes de laboratório para a determinação dos teores dos macronutrientes (N, P, K, S, Ca e Mg).

Para cada parcela havia a relação de árvores amostradas e a quantidade de biomassa em cada componente. Os conteúdos de nutrientes foram determinados multiplicando-se a quantidade de matéria seca, por espécie, pelo teor de nutriente. Como havia dados das espécies presentes em cada parcela, foram calculados os nutrientes médios na parcela.

\section{Processamento das imagens}

Descrição do Sensor

As principais características técnicas do satélite IKONOS II e de seus produtos estão resumidas na tabela 2. O satélite IKONOS II foi lançado no dia 24 de setembro de 1999, e está operacional desde o início de janeiro de 2000. Ele gera imagens com $4 \mathrm{~m}$ de resolução nas bandas multiespectrais e $1 \mathrm{~m}$ na banda pancromática. A resolução radiométrica das imagens é 11 bits (2048 níveis de cinza), o que possibilita um aumento no poder de contraste e de discriminação das imagens.

Tabela 2. Características do sensor.

Table 2. Sensor characteristics.

\begin{tabular}{|c|c|}
\hline \multicolumn{2}{|c|}{ Especificações do satélite IKONOS II e características do sensor } \\
\hline Altitude & $680 \mathrm{~km}$ \\
\hline Inclinação & $98,1^{\circ}$ \\
\hline Velocidade & $7 \mathrm{~km} / \mathrm{s}$ \\
\hline Sentido da Órbita & Descendente \\
\hline Duracão da Órbita & 98 minutos \\
\hline Tipo de Órbita & Sol-síncrona \\
\hline Resolução Espacial & Pancromática: $1 \mathrm{~m}$ / Multiespectral: $4 \mathrm{~m}$ \\
\hline \multirow[t]{5}{*}{ Bandas espectrais } & Pan $0.45-0.90 \mu \mathrm{m}$ \\
\hline & (MS-1) Azul 0.45-0.52 $\mu \mathrm{m}$ \\
\hline & (MS-2) Verde $0.52-0.60 \mu \mathrm{m}$ \\
\hline & (MS-3) Vermelho $0.63-0.69 \mu \mathrm{m}$ \\
\hline & (MS-4) Infravermelho próximo $0.76-0.90 \mu \mathrm{m}$ \\
\hline Imageamento & $13 \mathrm{~km}$ na vertical (cenas de $13 \mathrm{~km}$ x $13 \mathrm{~km}$ ) \\
\hline \multirow[t]{3}{*}{ Capacidade de Aquisição de imagens } & Faixas de $11 \mathrm{~km}$ x $100 \mathrm{~km}$ até $11 \mathrm{~km}$ x $1000 \mathrm{~km}$ \\
\hline & Mosaicos de até $12.000 \mathrm{~km}^{2}$ \\
\hline & $20.000 \mathrm{~km}^{2}$ de área imageada numa passagem \\
\hline \multirow[t]{4}{*}{ Freqüência de Revisita } & 2.9 dias no modo Pancromático \\
\hline & 1.5 dias no modo Multiespectral \\
\hline & Esses valores valem para latitude de $+/-40^{\circ}$. A \\
\hline & $\begin{array}{l}\text { freqüência de revisita para latitudes maiores será } \\
\text { menor, e maior para as latitudes perto do Equador. }\end{array}$ \\
\hline
\end{tabular}

Correção geométrica das imagens

Para a correção geométrica, foram coletados quinze pontos de apoio, utilizando-se um GPS (Global Positioning System) topográfico, com uma precisão de aproximadamente $50 \mathrm{~cm}$. A localização de cada ponto é um fator que deve ser considerado, pois o êxito na correção geométrica da imagem depende da fácil identificação do ponto na imagem e da distribuição desses pontos, que deve ser a mais uniforme possível. Os pontos foram então identificados na imagem de satélite em uma composição colorida, utilizando-se as bandas MS-3, MS-2 e MS-1. O método utilizado para fazer a reamostragem dos pixels foi o vizinho mais próximo. Esse método foi escolhido, porque preserva os DN's (Digital Numbers) da imagem, não envolvendo médias na reamostragem dos pixels. 
Conversão dos valores digitais numéricos em reflectância

Quando se realizam estudos relacionados ao conteúdo de umidade na vegetação ou da biomassa, é necessário estabelecer uma relação quantitativa entre os números digitais (DN's) da imagem e parâmetros do alvo. Deve-se realizar a conversão dos DN's para reflectância, com a finalidade de minimizar a variabilidade de condições de iluminação no comportamento espectral do alvo, no caso do trabalho na vegetação (Chuvieco, 1990).

Para realizar a correção atmosférica, utilizou-se a metodologia denominada de "correção do histograma por seus valores mínimos" (Histogram Minimum Method, HMM). A metodologia assume que as áreas (alvos) com forte absortividade (água e sombras) deveriam apresentar uma radiância espectral muito próxima de zero, mas na prática o histograma dos DN's da imagem sempre apresenta um mínimo superior a zero. Atribuiu-se esse valor ao efeito da dispersão da atmosfera. Pela metodologia, deve-se estabelecer uma banda de referência, preferencialmente a mais afetada pela dispersão, como a banda na região do azul (Watzlawick, 2003).

O fator de correção atmosférico para as outras bandas foi calculado utilizando-se a seguinte fórmula:

$$
D N_{i, j, k}=D N_{i, j, k}-D N_{\min , k}
$$

Onde: DN (número digital) no pixel $(\mathrm{I}, \mathrm{j})$ na banda $\mathrm{k}$ ajusta o DN mínimo dessa mesma banda. A conversão dos DN's para radiância leva em consideração os parâmetros de calibração do sensor IKONOS.

$$
L_{i, j, k}=D N_{i, j, k} x\left[\text { CalCoef }_{k}\right]
$$

Onde:

$\mathrm{L}_{\mathrm{i}, \mathrm{j}, \mathrm{k}}=$ valor da radiância do pixel $\mathrm{I}, \mathrm{j}$ na banda $\mathrm{k}, \mathrm{em} \mathrm{mW} / \mathrm{cm}^{2} \cdot \mathrm{sr}^{-1}$.

CalCoef $\mathrm{k}_{\mathrm{k}}=$ coeficiente de calibração da radiância $\mathrm{em} \mathrm{mW} / \mathrm{cm}^{2} \cdot \mathrm{sr}^{-1}$.

Os coeficientes utilizados para as bandas MS-1, MS-2, MS-3 e MS-4 foram 637, 573, 663 e 503, respectivamente.

A conversão dos valores de radiância para refletância considera parâmetros relacionados com o momento de aquisição da imagem e o posicionamento do sensor (ângulo zenital e horário da coleta da cena) e a distância normalizada terra-sol. Para isso utilizou-se a equação a seguir:

$$
R=\frac{\pi \cdot L \cdot r^{2}}{E \cdot \cos \theta}
$$

Onde:

$\mathrm{R}=$ reflectância (adimensional).

$\pi=3,14159265$.

$\mathrm{L}=$ radiância $\mathrm{em} \mathrm{mW} / \mathrm{cm}^{2} . \mathrm{sr}^{-1}$.

$\mathrm{r}=$ distância normalizada terra-sol, em unidades astronômicas.

$\theta=$ ângulo zenital solar no centro da imagem, em graus.

$\mathrm{E}=$ constante solar, $\mathrm{em} \mathrm{mW} / \mathrm{cm}^{2} \cdot \mathrm{sr}^{-1}$.

Localização das parcelas nas imagens

As parcelas para determinação de biomassa foram locadas dentro das parcelas utilizadas para o inventário florestal da fazenda. Após toda a vegetação ter sido retirada, foi tomado um ponto na área central de cada parcela com o auxílio do GPS (Global Positioning System) Leica-Topográfico SR-510. Por meio desse ponto, outros quatro pontos foram levantados, em cada extremidade da parcela, possibilitando assim a sua localização na imagem de satélite (Watzlawick, 2003).

Após o cálculo dos valores de reflectância para as bandas MS-1, MS-2, MS-3 e MS-4, foram determinadas as reflectâncias médias nas parcelas. As parcelas foram recortadas da imagem e uma média simples foi realizada para os valores digitais dos 9 pixels ( $3 \times 3$ pixels $)$ presentes dentro da parcela. 
Geração das imagens "Índice de Vegetação"

Para gerar as imagens contendo os índices de vegetação, foram utilizadas as bandas já com os valores de reflectância. Os índices de vegetação utilizados são apresentados na tabela 3. As parcelas também foram recortadas das imagens como no item anterior.

Tabela 3. Índices de vegetação.

Table 3. Vegetation indexes.

\begin{tabular}{ccc}
\hline Índice & Referência & Fórmula \\
\hline \multirow{2}{*}{ RVI } & ROUSE (1974) & MS 4 \\
& MS 3 \\
\hline \multirow{2}{*}{ NDVI } & ROUSE (1974) & $($ MS 4 - MS 3) \\
& (MS4 + MS 3) \\
\hline \multirow{2}{*}{ SAVI } & HUETE (1988) & $($ MS 4 - MS 3) \\
\hline
\end{tabular}

MS 3: banda no vermelho; MS 4: banda no infravermelho próximo; L: fator de correção para o solo; RVI: Razão de

Bandas; NDVI: Normalized Difference Vegetation Index; SAVI: Soil Adjusted Vegetation Index.

O valor de $\mathrm{L}$ faz com que os valores de brilho do solo exerçam uma influência menor na resposta espectral da vegetação e varia de 0 a 1 , dependendo da densidade da vegetação. Portanto locais com vegetação mais densa devem considerar $\mathrm{L}=0,25 \mathrm{e}$, no caso de vegetação mais rala ou mais aberta, $\mathrm{L}=1$. $\mathrm{O}$ valor $\mathrm{L}=0,5$ cabe à maioria dos tipos vegetacionais associados a uma grande variedade de solos, e esse foi o valor adotado (Huete, 1988).

\section{Análises estatísticas}

Foram gerados modelos para que se pudesse fazer a estimativa dos nutrientes para a área toda. Os dados provenientes das imagens de satélite, ou seja, os valores de reflectância médio nas parcelas nas bandas do azul, verde, vermelho e infravermelho próximo, e nos índices de vegetação, entraram no modelo como variáveis independentes. O conteúdo de macronutriente médio por parcela, obtido em campo, foi estipulado como variável dependente. A equação proposta para ajustar o modelo é uma equação linear do tipo:

$$
Y=b_{0}+b_{1} X_{1}+b_{2} X_{2}+b_{3} X_{3}+b_{4} X_{4}+b_{5} X_{5}+b_{6} X_{6}+b_{7} X_{7}
$$

A partir da matriz de correlação, foram verificadas quais variáveis apresentavam a maior correlação com a variável dependente $\mathrm{Y}$, ou seja, o nutriente. Foi utilizada uma equação para estimar cada nutriente (N, P, K, S, Ca e Mg). Utilizou-se o método de seleção de variáveis Stepwise (passo a passo), para definir quais variáveis $\mathrm{X}$ continuariam no modelo. Como indicativo de eliminação ou permanência no modelo, foi analisado o valor de F parcial.

Com a utilização desses modelos, foi possível o mapeamento de cada macronutriente para a Floresta Ombrófila Mista na área de estudo.

\section{RESULTADOS E DISCUSSÃO}

\section{Quantificação da biomassa e dos nutrientes nas parcelas}

Os valores estimados para a biomassa no fuste, casca, galhos, folhas e miscelânea das árvores são apresentados na tabela 4. Primeiramente foram calculados a biomassa seca nas parcelas e depois os valores foram extrapolados para hectare. Esses valores foram utilizados para a determinação dos conteúdos de nutrientes.

Os valores dos conteúdos de macronutrientes na biomassa seca são apresentados na tabela 5 . Nota-se que os maiores valores de nutrientes estão presentes nas folhas, com exceção do cálcio que, pela sua imobilidade na planta, se acumula na casca das árvores. 
Tabela 4. Biomassa média das espécies amostradas nas parcelas com DAP $>10 \mathrm{~cm}$ da Floresta Ombrófila Mista, em Ton.ha ${ }^{-1}$.

Table 4. Average biomass $\left(\right.$ Ton. $^{-1}{ }^{-1}$ ) of sampled species with DAP $>10 \mathrm{~cm}$ in Mixed Ombrophylus Forest.

\begin{tabular}{|c|c|c|c|c|c|c|}
\hline Parcela & Fuste & Casca & Galhos & Folhagem & Miscelânea & TOTAL \\
\hline$\overline{1}$ & 25,6021 & 5,0840 & 22,5451 & 2,2160 & 0,2201 & 55,6673 \\
\hline 2 & 130,0256 & 2,7210 & 253,8829 & 2,5292 & 9,5043 & 398,663 \\
\hline 3 & 78,6660 & 6,0646 & 72,8090 & 2,4076 & 1,7285 & 161,6757 \\
\hline 4 & 9,1438 & 1,1736 & 11,2625 & 0,9094 & 0,0903 & 22,5796 \\
\hline 5 & 145,3472 & 19,4451 & 213,1164 & 4,8396 & 4,2369 & 386,9852 \\
\hline 6 & 25,5535 & 3,8889 & 23,6979 & 1,3285 & 0,0292 & 54,498 \\
\hline 7 & 63,4965 & 25,0785 & 33,9438 & 5,8243 & 0,5049 & 128,848 \\
\hline 8 & 132,3806 & 40,3507 & 6229,3100 & 13,1083 & 2,1563 & 6417,3059 \\
\hline 9 & 34,5648 & 9,5206 & 27,0708 & 6,1015 & 0,4770 & 77,7347 \\
\hline 10 & 64,7229 & 43,4889 & 25,4042 & 10,2597 & 0,4236 & 144,2993 \\
\hline 11 & 100,9090 & 21,3792 & 199,4201 & 9,0250 & 2,9597 & 333,693 \\
\hline 12 & 194,3042 & 24,2042 & 227,8257 & 9,7826 & 456,1167 & 912,2334 \\
\hline 13 & 76,6785 & 6,1056 & 143,3875 & 4,9625 & 4,1035 & 235,2376 \\
\hline 14 & 29,4451 & 3,8264 & 33,2416 & 2,3146 & 0,2451 & 69,0728 \\
\hline 15 & 104,8474 & 16,5870 & 146,6285 & 5,5438 & 3,8743 & 277,481 \\
\hline 16 & 84,6111 & 8,9778 & 102,1942 & 3,6693 & 0,7215 & 200,1739 \\
\hline 17 & 271,4681 & 155,7764 & 133,6951 & 8,1903 & 5,0056 & 574,1355 \\
\hline 18 & 36,7118 & 4,8431 & 76,5299 & 3,6056 & 0,4238 & 122,1142 \\
\hline 19 & 74,7055 & 33,8556 & 27,6903 & 6,5763 & 0,1639 & 142,9916 \\
\hline 20 & 30,8229 & 5,9903 & 9,1750 & 1,0771 & 0,0639 & 47,1292 \\
\hline MÉDIA & 85,70033 & 21,918075 & 400,64153 & 5,21356 & 24,652455 & 538,12595 \\
\hline
\end{tabular}

Tabela 5. Conteúdos médios dos macronutrientes $\left(\right.$ Ton.ha $\left.{ }^{-1}\right)$ na biomassa das espécies com DAP $>10 \mathrm{~cm}$ da Floresta Ombrófila Mista.

Table 5. Macronutrients average contents $\left(\text { Ton. }^{-1}\right)^{-1}$ in the biomass of species with DAP $>10 \mathrm{~cm}$ in Mixed Ombrophylus Forest.

\begin{tabular}{llllll}
\hline Nutriente & Madeira & Casca & Galhos & Folhas & Miscelânea \\
\hline Nitrogênio & 3,2023 & 8,0786 & 6,4640 & 21,8977 & 14,6530 \\
Enxofre & 0,8503 & 1,3252 & 1,0253 & 2,0124 & 2,0835 \\
Fósforo & 0,3457 & 0,3992 & 0,5262 & 1,3758 & 1,0847 \\
Potássio & 6,0895 & 6,7137 & 7,1478 & 10,2991 & 7,9044 \\
Cálcio & 2,4104 & 19,0858 & 7,1391 & 9,2631 & 7,4575 \\
Magnésio & 1,0209 & 1,5039 & 1,1860 & 3,2835 & 1,7815 \\
\hline
\end{tabular}

\section{Valores de reflectância e Índices de Vegetação}

Os valores de reflectância referentes a cada banda e aos índices de vegetação são apresentados na tabela 6. Esses valores entraram no modelo como variáveis independentes. A reflectância média nas parcelas foi a seguinte: 0,018667 para a banda azul (MS-1), 0,030048 para a banda verde (MS-2), 0,02466903 para a banda vermelha (MS-3), 0,2522353 para a banda no infravermelho próximo (MS-4). Para os índices de vegetação, as médias foram: 10,451681 para a Razão de Bandas (MS-3/MS-4), 0,820012 para o NDVI ((MS-3 - MS-4)/ (MS-3 + MS-4)) e 0,437605 para o SAVI ((MS-3 - MS-4)/ (MS$3+\mathrm{MS}-4+\mathrm{L}) \times 1+\mathrm{L})$.

O que se pode notar é que os valores de reflectância na banda individual do infravermelho próximo são bem mais altos do que nas demais bandas. Isso ocorre porque nessa parte do espectro eletromagnético a curva de reflectância da vegetação apresenta um aumento significativo. Os índices de 
vegetação foram criados para realçar a vegetação em uma imagem de satélite. Isso se confirma quando comparamos os valores de reflectância nos índices Razão, NDVI e SAVI com os valores de reflectância das bandas individuais.

Tabela 6. Valores de reflectância médio por pixel em cada parcela (adimensional).

Table 6. Reflectance average values for pixel in each sample.

\begin{tabular}{lccccccc}
\hline Parcela & BLUE $^{\mathbf{1}}$ & $\mathbf{G R E E N}^{\mathbf{2}}$ & $\mathbf{R E D}^{\mathbf{3}}$ & $\mathbf{N I R}^{\mathbf{4}}$ & $\mathbf{R A Z A O}^{\mathbf{5}}$ & $\mathbf{N D V I}^{\mathbf{6}}$ & SAVI $^{\mathbf{7}}$ \\
\hline 1 & 0,027443 & 0,037535 & 0,028300 & 0,200574 & 7,087349 & 0,752700 & 0,354534 \\
2 & 0,023374 & 0,038201 & 0,027031 & 0,240557 & 8,899138 & 0,797962 & 0,417265 \\
3 & 0,022838 & 0,035353 & 0,029867 & 0,254915 & 8,534998 & 0,790246 & 0,430147 \\
4 & 0,024420 & 0,038976 & 0,028545 & 0,237683 & 8,326502 & 0,785557 & 0,409416 \\
5 & 0,019361 & 0,032638 & 0,028993 & 0,267948 & 9,241817 & 0,804722 & 0,449760 \\
6 & 0,021280 & 0,034516 & 0,029073 & 0,321405 & 11,054937 & 0,834093 & 0,515589 \\
7 & 0,019362 & 0,028893 & 0,028155 & 0,217738 & 7,733546 & 0,770998 & 0,381254 \\
8 & 0,014826 & 0,030167 & 0,018770 & 0,213762 & 11,388418 & 0,838559 & 0,399283 \\
9 & 0,017582 & 0,031696 & 0,024356 & 0,317870 & 13,051190 & 0,857663 & 0,522748 \\
10 & 0,015175 & 0,026184 & 0,025921 & 0,253523 & 9,780653 & 0,814482 & 0,438009 \\
11 & 0,018315 & 0,028893 & 0,027149 & 0,222001 & 8,177041 & 0,782065 & 0,390146 \\
12 & 0,016396 & 0,026540 & 0,020446 & 0,209852 & 10,263836 & 0,822441 & 0,389032 \\
13 & 0,014129 & 0,027404 & 0,018105 & 0,231820 & 12,804130 & 0,855116 & 0,427473 \\
14 & 0,016571 & 0,024087 & 0,022960 & 0,232724 & 10,136249 & 0,820406 & 0,416373 \\
15 & 0,016571 & 0,027148 & 0,021116 & 0,251986 & 11,933221 & 0,845359 & 0,447941 \\
16 & 0,017001 & 0,028391 & 0,024077 & 0,267882 & 11,125839 & 0,835063 & 0,461774 \\
17 & 0,017966 & 0,027334 & 0,026144 & 0,279214 & 10,679924 & 0,828766 & 0,471349 \\
18 & 0,018489 & 0,027923 & 0,024468 & 0,264568 & 10,812811 & 0,830692 & 0,456443 \\
19 & 0,016222 & 0,025984 & 0,019776 & 0,276819 & 13,997972 & 0,866649 & 0,484017 \\
20 & 0,016013 & 0,023103 & 0,020127 & 0,281864 & 14,004052 & 0,866703 & 0,489538 \\
\hline MÉDIA & 0,0186667 & 0,0300483 & 0,024669 & 0,2522353 & 10,451681 & 0,8200121 & 0,4376046 \\
\hline
\end{tabular}

Fonte: Watzlawick (2003).

1 - reflectância na banda do azul; 2 - reflectância na banda do verde; 3 - reflectância na banda do vermelho; 4 - reflectância na banda do infravermelho próximo; 5, 6 e 7 - índices de vegetação.

\section{Análises estatísticas}

Os valores das correlações estão apresentados nas tabelas 7 e 8 . Verifica-se a baixíssima correlação dos nutrientes com as bandas e índices de vegetação quando se utiliza o conteúdo dos nutrientes em todos os componentes da árvore somados, e o aumento dessas correlações quando é utilizado somente o conteúdo de nutrientes presentes nas folhas. Isso ocorre porque a maioria dos satélites, com exceção do radar, não possui uma alta capacidade de penetração no dossel florestal, e a reflectância que chega até o sensor geralmente está associada às copas das árvores, especialmente em florestas nativas.

Com base nos resultados obtidos nas tabelas, optou-se por utilizar somente os dados referentes às folhas para o mapeamento dos nutrientes.

Tabela 7. Coeficientes de correlação utilizando todos os componentes da árvore (fuste, casca, galhos, folhas e miscelânea).

Table 7. Correlation coefficients using all the components of the tree (trunk, bark, branches, leaves and mixture).

\begin{tabular}{lcccccc}
\hline & Nitrogênio & Enxofre & Fósforo & Potássio & Cálcio & Magnésio \\
\hline BLUE & $-0,119554262$ & $-0,160423553$ & $-0,065699448$ & $-0,25613418$ & $-0,226638135$ & $-0,234578666$ \\
GREEN & 0,027544358 & $-0,039500978$ & 0,080592101 & $-0,141273944$ & $-0,127066388$ & $-0,173248083$ \\
RED & $-0,07785473$ & $-0,016148874$ & $-0,105835824$ & $-0,161491401$ & $-0,112641566$ & $-0,306143413$ \\
NIR & $-0,265366451$ & $-0,205550135$ & $-0,278391194$ & $-0,215872486$ & $-0,111431092$ & $-0,009443352$ \\
RAZAO & $-0,145926304$ & $-0,153352306$ & $-0,135170753$ & $-0,039085697$ & $-0,017793539$ & 0,243044823 \\
NDVI & $-0,064603826$ & $-0,078828748$ & $-0,057995234$ & 0,031920915 & 0,056615035 & 0,257784205 \\
SAVI & $-0,23738559$ & $-0,192279293$ & $-0,248378499$ & $-0,168622647$ & $-0,075941366$ & 0,067597209 \\
\hline
\end{tabular}


Tabela 8. Coeficientes de correlação utilizando somente as folhagens.

Table 8. Correlation coefficients using only the foliage.

\begin{tabular}{lcccccc}
\hline & Nitrogênio & Enxofre & Fósforo & Potássio & Cálcio & Magnésio \\
\hline BLUE & $-0,600564159$ & $-0,550124$ & $-0,577400581$ & $-0,599969704$ & $-0,485442898$ & $-0,52037514$ \\
GREEN & $-0,431635877$ & $-0,3746055$ & $-0,393223294$ & $-0,442711496$ & $-0,311744328$ & $-0,325083319$ \\
RED & $-0,398420513$ & $-0,4021024$ & $-0,383542374$ & $-0,425370962$ & $-0,212949259$ & $-0,358970935$ \\
NIR & $-0,316437214$ & $-0,3547361$ & $-0,218226159$ & $-0,218524209$ & $-0,135157397$ & $-0,184420672$ \\
RAZAO & 0,077609301 & 0,0567528 & 0,13357355 & 0,190155241 & 0,055487957 & 0,14424821 \\
NDVI & 0,141495635 & 0,1148654 & 0,181729072 & 0,20957946 & 0,095416129 & 0,177174445 \\
SAVI & $-0,229619737$ & $-0,2706539$ & $-0,137279902$ & $-0,127099052$ & $-0,089576999$ & $-0,110442673$ \\
\hline
\end{tabular}

\section{Geração dos modelos}

Para gerar as equações, foi utilizado o método de seleção de variáveis Stepwise. Após eliminar as variáveis que não estavam contribuindo significativamente para o modelo, foram ajustadas as equações para cada nutriente, apresentadas na tabela 9.

Tabela 9. Equações ajustadas para cada nutriente.

Table 9. Adjusted equations for each nutrient.

\begin{tabular}{|c|c|c|c|c|c|}
\hline Nutriente & Equação Ajustada & $\begin{array}{c}\mathbf{R}^{2} \\
\text { Ajustado }\end{array}$ & $\begin{array}{c}\text { Erro Padrão } \\
\%\end{array}$ & $\mathbf{F}$ & $\begin{array}{c}\text { Probabilidade } \\
\%\end{array}$ \\
\hline $\mathrm{N}$ & $\begin{array}{l}\mathrm{N}=0,986890-27,721770 * \mathrm{BLUE}- \\
0,029637 * \mathrm{RAZÃO}\end{array}$ & 0,5256 & 6,4718 & $11,5^{* *}$ & $0,068 \%$ \\
\hline $\mathrm{S}$ & $\begin{array}{l}\mathrm{S}=0,093182-1,84144 * \text { BLUE }-0,09988 * \\
\mathrm{SAVI}\end{array}$ & 0,4559 & 0,6886 & $8,96^{* *}$ & 0,2189 \\
\hline $\mathrm{P}$ & $\begin{array}{l}\mathrm{P}=0,156168-2,137157 * \text { BLUE - 0,128161 } \\
* \mathrm{NDVI}\end{array}$ & 0,3996 & 0,6031 & $7,32 * *$ & 0,5082 \\
\hline $\mathrm{K}$ & $\begin{array}{l}\mathrm{K}=1,143371-16,2131 * \mathrm{BLUE}-0,92311 \\
* \mathrm{NDVI}\end{array}$ & 0,4162 & 4,4902 & $7,77 * *$ & 0,4001 \\
\hline $\mathrm{Ca}$ & $\begin{array}{l}\mathrm{Ca}=1,915491-24,1921 * \mathrm{BLUE}-1,66845 \\
* \text { NDVI }\end{array}$ & 0,3133 & 7,800 & $5,33 * *$ & 1,5911 \\
\hline $\mathrm{Mg}$ & $\mathrm{Mg}=0,081677-3,02089 *$ BLUE & 0,2302 & 1,7971 & $6,68 * *$ & 1,8663 \\
\hline
\end{tabular}

Nota-se que a banda azul apareceu em todas as equações e que as bandas do vermelho e do infravermelho próximo estão presentes nos índices de vegetação NDVI, SAVI e RAZÃO, já que elas fazem parte das fórmulas para o cálculo desses índices. Essas bandas então foram as que mais contribuíram para gerar as equações dos nutrientes.

Os coeficientes de correlação baixos podem estar relacionados ao pequeno número de parcelas na área de estudo, visto que a Floresta Ombrófila Mista, assim como a maioria das florestas nativas, apresenta uma alta diversidade de espécies. As amostras não foram proporcionais às áreas ocupadas por cada estágio sucessional. A amostragem sistemática possibilitaria que os dados de biomassa e, conseqüentemente, os conteúdos de nutrientes fossem agrupados em classes, diminuindo assim a discrepância entre os dados.

Outro fato que pode estar influenciando no coeficiente de correlação é a relação da biomassa com a resposta espectral da vegetação. Com o aumento da cobertura vegetal, espera-se que a reflectância na região do vermelho diminua e a reflectância na região do infravermelho próximo aumente proporcionalmente ao aumento da camada de folhas em um dossel. Isso na prática não ocorre, porque há um ponto de saturação para ambas as regiões do espectro eletromagnético, ou seja, o incremento de biomassa, a partir de um certo ponto, não é mais representado na curva espectral da vegetação (PONZONI, 2001). O mesmo ocorre para os índices de vegetação, pois a maioria deles é composto pelas bandas do vermelho e infravermelho próximo. Como a biomassa de folhas está diretamente relacionada com o conteúdo de nutrientes, esse fato também pode influenciar na quantificação de nutrientes por meio de imagens de sensores remotos. 


\section{Geração dos mapas de nutrientes}

As equações geradas no item anterior foram aplicadas às imagens de satélite por meio do software ENVI 3.2, e foram geradas imagens para cada macronutriente, em que cada pixel armazenava o conteúdo de nutriente. Para uma melhor visualização da distribuição dos macronutrientes, foram atribuídas classes para os diferentes conteúdos de nutrientes. $\mathrm{O}$ mapa de nitrogênio para a área é apresentado na figura 3.

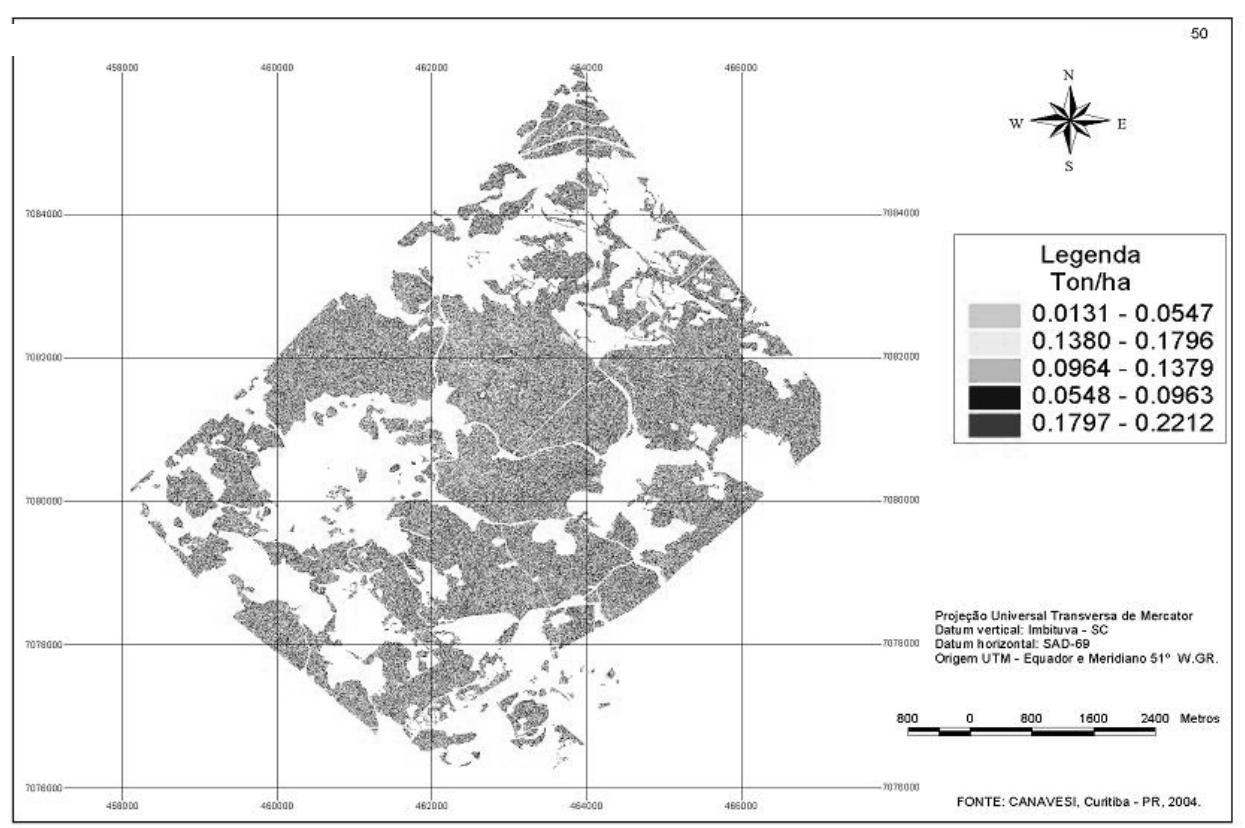

Figura 3. Conteúdo de nitrogênio (Ton.ha $\left.{ }^{-1}\right)$ nas folhas da Floresta Ombrófila Mista, General Carneiro, PR. Figure 3. Nitrogen content (Ton.ha-1) in the leaves of Mixed Ombrophylous Forest, General Carneiro, PR.

\section{CONCLUSÕES}

Os teores de macronutrientes geralmente apresentaram valores mais elevados nas folhas, com exceção do elemento $\mathrm{Ca}$, que apresentou um teor maior na casca. Os teores médios dos macronutrientes presentes nas folhas amostradas nas espécies com diâmetro $\leq 10 \mathrm{~cm}$ seguiram a seguinte ordem: $\mathrm{N}>\mathrm{K}>$ $\mathrm{Ca}>\mathrm{Mg}>\mathrm{S}>\mathrm{P}$.

As análises estatísticas mostraram uma baixa correlação entre as variáveis dependentes (nutrientes) e as variáveis independentes (valores de reflectância) quando se utilizaram os teores de nutrientes em todos os componentes das árvores somados (fuste + casca + galhos + folhas + miscelânea). Os maiores coeficientes de correlação foram: N 0,26, S 0,20 e P 0,27 (na banda do infravermelho próximo); K 0,25 e Ca 0,22 (na banda do azul) e Mg 0,30 (na banda do vermelho).

Os maiores coeficientes de correlação entre as variáveis dependentes e as independentes, quando se utilizou somente o teor de nutrientes nas folhas, foram: N 0,60, S 0,55, P 0,57, K 0,59, Ca 0,48 e Mg 0,52. Essas correlações ocorreram sempre em relação aos valores de reflectância na banda do azul.

Os baixos valores de correlação podem estar relacionados com o método de amostragem utilizado no trabalho, bem como com a saturação apresentada em alguns comprimentos de onda (faixa do vermelho e infravermelho próximo), fazendo com que a reflectância não corresponda à real quantidade de biomassa da área.

Salienta-se a importância da quantificação de nutrientes em florestas nativas de maneira indireta, das quais se têm poucas informações, visto a quantidade de ecossistemas existentes e a alta diversidade dentro de cada um deles. 


\section{REFERÊNCIAS}

CALDEIRA, M. V. W. Biomassa, serapilheira acumulada e nutrientes em uma Floresta Ombrófila Mista Montana em General Carneiro. Curitiba, 2003. 169f. Tese (Doutorado em Ciências Florestais) Setor de Ciências Agrárias, Universidade Federal do Paraná,

CERRI, C. C.; CHAPLOT, V.; CERRI, C. E. P. Ciclagem de nutrientes e sustentabilidade agrícola. [S.1.]: Centro de Energia Nuclear na Agricultura, 2001.

CHUVIECO, E. Fundamentos de teledetección espacial, Madrid: [s.n.], 1990. 568p.

CURRAN, P. J. Principles of remote sensing. New York; [s.n.],1986. 282 p.

DONG, J.; KAUFMANN, R. K.; MYNENI, R. B.; TUCKER, C. J.; KAUPPI, P. E.; LISKI, J.; BUERMANN, W.; ALEXEYEV, V.; HUGHES, M. K. Remote sensing estimates of boreal and temperate forest wood biomass: carbon pools, sources, and sinks. Remote Sensing of Environment, New York, n. 84, p. 393-410, 2003.

FODDY, G. M.; BOYD, D. S.; CUTLER, M. E. J. Predictive relations of tropical forest biomass from Landsat TM data and their transferability between regions. Remote Sensing of Environment, New York, n. 85, p. 463-474, 2003.

GAVEAU, D. L. A.; BALZTER, H.; PLUMMER, S. Forest wood biomass classification with satelitebased radar coherence over $900.000 \mathrm{Km}^{2}$ in Central Siberia. Forest Ecology and Management, Amsterdam, n. 174, p. 65-75, 2003.

HOFFER, R. M. Biological and physical considerations in applying computer-aided analysis techniques to remote sensor data. In: SWAIN, P.H.; DAVIS, S.M., (Eds.). Remote sensing the quantitative approach, New York: McGraw Hill, 1978. p. 89-228.

HUETE, A. R. Soil spectral effects on vegetation discrimination. Arizona, 1988, 208 p. Tese (Doutorado) - Universidade do Arizona.

LACRUZ, P. M. S.; SHIMABUKURO, Y. E.; WILliAMS, M.; RENNÓ, C. D.; HERBERT, D.; RASTETTER, E. B. Utilização do sensoriamento remoto e dados de campo para modelagem das atividades biogeoquímicas na Floresta Nacional de Tapajós. In: SIMPOSIO BRASILEIRO DE SENSORIAMENTO REMOTO, 10., 2001. Foz do Iguaçu. Anais... \{S.1.: s.n.], 2001. Sessão pôster. 1 CD-ROM.

LARCHER, W. (1929) Ecofisiologia vegetal. São Paulo: EPU, 1986. 319p.

MALAVOLTA, E. Absorção e transporte de íons. In: FERRI, M.G. (Coord.). Fisiologia Vegetal, São Paulo: EPU: Ed. da Universidade de São Paulo. 1979. v. 1, p. 77-98.

MILlER, H. G. Dynamics of Nutrient Cycling in Plantation Ecosystems. In: BOWEN, G. D.; NAMBIAR, E. K. S. Nutrition of plantation forests. London: Academic, 1984, p. 53-78.

NILSSON, L.; WIKLUND, K. Nutrient balance and P, K, Ca, Mg, S and B accumulation in a Norway spruce stand following ammonium sulphate application, fertigation, irrigation, drought an $\mathrm{N}$-freefertilization. In: NILSSON, L. O.; HÜTTL, R. F.; JOHANSSON, U. T. (Eds.) Nutrient uptake and cycling in forest ecosystems. USA: Kluwer Academic, 1995. 685 p.

PONZONI, F. J. Comportamento espectral da vegetação. In: Meneses, P. R. e Netto, J. S. M. (Orgs.) Sensoriamento remoto: reflectância dos alvos naturais. Brasília, DF:UNB. 2001. p. 157-195.

PROPRIEDADES ópticas da vegetação e do solo. Disponível em: <www.cis.rit.edu/class/simg553_01/agriculture.html> Acesso em: jul. 2004.

SANTOS, V. D. Ciclagem de nutrientes minerais em mata tropical subcaducifólia dos planaltos do Paraná (Parque Estadual Vila Rica do Espírito Santo - Fênix/PR). São Carlos, 1989. 387 f. Tese (Doutorado) - Universidade Federal de São Carlos. 
SPACE IMAGING. Disponível em: <www.spaceimaging.com> Acesso em: jul. 2004.

THIAM, A.; EASTMAN, R. Vegetation Indices. In: Guide to and image processing. [S.1.: s.n.],1999. v. 2. IDRISI32.

VERBYLA, D. Satellite remote sensing of natural resources. New York: [s.n.], 1995. 198 p.

WATZLAWICK, L. F. Análise e estimativa de biomassa e carbono em Floresta Ombrófila Mista e plantações florestais a partir de dados do satélite IKONOS II. Curitiba, 2003. 119 f. Tese (Doutorado em Ciências Florestais) - Setor de Ciências Agrárias, Universidade Federal do Paraná.

YAMAJI, F. M. Análise fractal de uma Floresta Ombrófila Mista através de imagem de satélite. Curitiba, 2001. 91f. Dissertação (Mestrado em Ciências Florestais) - Setor de Ciências Agrárias, Universidade Federal do Paraná,. 2001.

ZERBINI, N. J. Estimativa de fitomassa aérea em região de floresta tropical com uso de dados de TM-Landsat 5 e HRV-SPOT 1. São José dos Campos, 1992. 127f. Tese (Doutorado em Sensoriamento Remoto) - Instituto Nacional de Pesquisas Espaciais. (INPE-5500-TDI/515). 